\title{
Acute cocaine treatment enhances the antagonistic allosteric adenosine A2A-dopamine D2 receptor-receptor interactions in rat dorsal striatum without increasing significantly extracellular dopamine levels
}

\author{
Wilber Romero-Fernandez ${ }^{1,2} \cdot$ Zilong Zhou $^{2,3} \cdot$ Sarah Beggiato $^{4} \cdot$ Karolina Wydra $^{5} \cdot$ Malgorzata Filip $^{5}$. \\ Sergio Tanganelli ${ }^{6}$. Dasiel O. Borroto-Escuela ${ }^{2,7,8} \cdot$ Luca Ferraro $^{4} \cdot$ Kjell Fuxe $^{2}$
}

Received: 30 September 2019 / Revised: 26 November 2019 / Accepted: 3 December 2019 / Published online: 2 March 2020

(c) The Author(s) 2020

\begin{abstract}
Background Antagonistic adenosine A2A receptor (A2AR)-dopamine D2 receptor (D2R) receptor-receptor interactions have previously been demonstrated in A2AR-D2R heteroreceptor complexes in the rat dorsal striatum. They mainly involve a reduction of affinity in the high-affinity component of the D2R agonist binding site upon activation in vivo of the A2AR by an A2AR agonist. Upon cocaine self-administration, this antagonistic A2AR-D2R interaction disappeared in the dorsal striatum. Methods In the current experiments, it was tested whether such modifications in the antagonistic A2AR-D2R receptorreceptor interactions can develop also after an acute systemic injection of a low cocaine dose $(1 \mathrm{mg} / \mathrm{kg}$; sc).

Results Microdialysis experiments indicated that acute cocaine did not significantly alter the extracellular dopamine levels in the dorsal striatum of the awake Wistar rats. Competition dopamine receptor binding experiments demonstrated that in the acute cocaine group, the A2AR agonist CGS-21680 produced significantly larger increases in the D2R $K_{\mathrm{i} \text {, High }}$ values (reduction of high-affinity) versus the saline-injected (i.e. control) group. Furthermore, in the dorsal striatum membrane preparation from acute cocaine-injected rats, CGS-21680 also produced significant increases in the D2R $K_{\mathrm{i} \text {, Low }}$ values (reduction of low-affinity) and in the proportion of D2Rs in the high-affinity state (RH). Such significant effects were not observed with CGS-21680 in the control group.

Conclusions The molecular mechanism involved in the acute cocaine-induced increase in the antagonistic allosteric A2ARD2R receptor-receptor interactions may be an increased formation of higher-order complexes A2AR-D2R-sigma1R in which cocaine by binding to the sigma1 $R$ protomer also allosterically enhances the inhibitory A2AR-D2R interaction in this receptor complex.
\end{abstract}

Keywords Cocaine $\cdot$ Adenosine A2A receptor · Dopamine D2 receptor $\cdot$ Sigma1 receptor $\cdot$ Heteroreceptor complexes

\section{Introduction}

It is established that there exist antagonistic adenosine A2A receptor (A2AR)-dopamine (DA) D2 receptor (D2R) interactions in higher-order A2AR-D2R heteroreceptor complexes in cellular models and in the rat dorsal striatum, as

Wilber Romero-Fernandez and Zilong Zhou have contributed equally to this work.

Kjell Fuxe

Kjell.Fuxe@ki.se

Extended author information available on the last page of the article demonstrated with biochemical binding techniques using $\mathrm{D} 2 \mathrm{R}$ radioligands and proximity ligation assay [1-16]. This is also in agreement with early behavioral findings in hemiparkinsonian rats [17]. The antagonistic modulation of the $\mathrm{D} 2 \mathrm{R}$ recognition by the A2AR agonist mainly involved a reduction of affinity in the high-affinity component of the D2R agonist binding site. It is of interest that following cocaine self-administration, the A2AR agonist-induced antagonistic modulation of the dorsal striatal D2-likeR agonist high-affinity binding site no longer develops [7]. This dysfunction/disruption of the dorsal striatal A2AR-D2 heteroreceptor complexes induced by cocaine self-administration might be involved in the development of either 
habit-forming learning and/or compulsive drug-seeking or locomotor sensitization by enhanced D2R protomer signaling [18]. From a mechanistic point of view, these effects may be related to a reorganization of the dorsal striatal A2AR-D2R heteroreceptor complexes and their balance with the D2R homoreceptor complexes upon the maintenance of cocaine self-administration [13]. It may be produced by cocaine-induced rises in extracellular DA levels via cocaine-induced blockade of the DA transporter (DAT) that favours the formation of $\mathrm{D} 2 \mathrm{R}$ homoreceptor complexes over A2AR-D2R heteroreceptor complexes $[13,19]$. As a consequence, the antagonistic A2AR-D2R receptor-receptor interactions become markedly and significantly reduced [7]. Other mechanism(s) can, however, also be involved. It has been reported that cocaine-self-administration produced a lowering in the density of D2R-Sigma1R heteroreceptor complexes in the dorsal striatum [13].

The sigma1 $\mathrm{R}$ is an adaptor/chaperone protein that is present in part on the plasma membrane [20,21] but also exists at the interface of the mitochondria and endoplasmic reticulum (ER), both targets for cocaine [21, 22]. Upon binding and activating the ER sigma1R, cocaine can translocate it to the plasma membrane. The unprotonated (base) form of cocaine is in equilibrium with its protonated form under physiological conditions. This form can pass the plasma membrane in view of its lipophilic and neutral properties [23]. Cocaine possesses a high affinity for the sigma1R [13, $21,24,25]$. In the plasma membrane, the sigma1R can inter alia form receptor complexes with D1Rs and D2Rs [26-28].

In the current study, we have, therefore, investigated if an acute systemic injection of cocaine, in a low dose that still binds to the sigma1R [21, 29] but does not increase extracellular DA levels in the dorsal striatum [30,31], could affect the antagonistic A2AR-D2R receptor-receptor interactions in rat dorsal striatum. The existence of a higher-order A2AR-D2R-Sigma1R heteroreceptor complex has recently been proposed [8].

\section{Materials and methods}

\section{Animals}

Animals arrived, were housed and tested according to the guidelines for the Care and Use of Laboratory Animals [32-34]. Adult male Wistar rats (250-300 g; Charles River S.R.L., Lecco, Italy) were used. The animals were housed in cages in groups of five animals at a temperature and relative humidity-controlled environment with a regular $12 \mathrm{~h}$ light-dark cycle and had free access to food and water. After arrival the animals were adapted to the environment for at least 1 week before the experiment. The experimental procedures performed in this study were in accordance with the European Communities Council Directive of September 2010 (2010/63/EU) and were approved by the Italian Ministry of Health.

\section{Microdialysis experiments}

The surgery with the microdialysis probe implantation into the right or left striatum and microdialysis experiments were performed based on the methods described previously [35, 36]. A microdialysis probe of concentric design (molecular weight cut-off, $20 \mathrm{kDa}$; CMA 12; outer diameter, $0.5 \mathrm{~mm}$; length of dialysing membrane, $2 \mathrm{~mm}$; Carnegie Medicine, Stockholm, Sweden) was used. The coordinates relative to the bregma were as follows: anterior (A) $+0.3 \mathrm{~mm}$; lateral (L) +3.1 mm; ventral (V) - 7.5 mm.

$36 \mathrm{~h}$ from implantation, the microdialysis experiments were performed in awake freely moving rats. Perfusates were collected every $20 \mathrm{~min}$ in vials maintained at $4{ }^{\circ} \mathrm{C}$ and protected from the light with aluminum foils to prevent DA degradation. After three stable basal DA values were obtained, cocaine [Cocaine $\mathrm{HCl}$, Sigma Chemicals, St. Louis, MO, USA (dissolved in saline $0.9 \% \mathrm{Na} \mathrm{Cl}$ solution) was subcutaneously injected at the dose of $1 \mathrm{mg} / \mathrm{kg}$ body weight, and further nine samples were collected (total experimental period $=240 \mathrm{~min} ; 12$ perfusate samples). Control rats were treated with a subcutaneous saline injection. Coronal sections were used to verify the position of the dialysis probe. Only those animals in which the probe was correctly located were included in the study [37].

Dopamine level was analyzed by high-performance liquid chromatography (Ultimate 3000 System from Dionex, Sunnyvale, CA, USA) with coulo-chemical detection (Coulochem III model 5300, ESA Inc., Chelmsford, MA, USA). The chromatographic data were analyzed by a Chromeleon v. 6.80 (Dionex) software. The values were not corrected for in vitro probe recovery, which was around 15\% [35].

\section{Binding experiments}

For the binding experiments, adult male Wistar rats were subcutaneously injected with cocaine $(1 \mathrm{mg} / \mathrm{kg}$; sc) or saline solution. $1 \mathrm{~h}$ after the acute cocaine or vehicle administration, the rats were sacrificed, and the dorsal striatum was dissected out and immediately frozen on dry ice and stored at $-80{ }^{\circ} \mathrm{C}$. The brain membrane preparation $(0.15 \mathrm{mg} / \mathrm{ml})$ and $\left[{ }^{3} \mathrm{H}\right]$-raclopride competition assays with minor modifications were performed according to previously published methods [9, 28].

$\left[{ }^{3} \mathrm{H}\right]$-raclopride $(75 \mathrm{Ci} / \mathrm{mmol}$, Novandi Chemistry AB, Sweden), a $\mathrm{D} 2$ receptor antagonist [7] competing with quinpirole for binding to D2-like receptors in dorsal striatal membrane preparations was used to determine the percent $\mathrm{D} 2 \mathrm{R}$ in the high-affinity state $(\mathrm{RH})$, the D2R high affinity $\left(K_{\mathrm{i}, \mathrm{High}}\right)$, 
and D2R low affinity $\left(K_{\mathrm{i}, \text { Low }}\right)$ values. (+)-Butaclamol (100 $\mu \mathrm{M}$, Sigma-Aldrich, Sweden) was used to determine the non-specific binding. As A2AR agonist, CGS-21680 (100 nM, Sigma-Aldrich, Sweden) was used. The A2AR antagonist ZM-241385 (1 $\mu$ M, Sigma-Aldrich, Sweden) was used as control. The amount of bound $\left[{ }^{3} \mathrm{H}\right]$-raclopride was determined by liquid scintillation spectrometry.

\section{Statistical analysis}

The number of rats $(n)$ in each group is indicated in figure legends. Microdialysis data were analyzed by two-way analysis of variance (ANOVA). Binding experiments data were obtained by nonlinear regression analysis employing GraphPad Prism 5.0 (GraphPad Software Inc., San Diego, $\mathrm{CA})$. The values from the control vehicle-treated group and acute cocaine group without CGS-21680 were compared by unpaired Student's t-test. The absolute values of D2R $K_{\mathrm{i}, \text { High }}$, $K_{\mathrm{i}, \text { Low }}$ and RH induced by A2AR agonist CGS-21680 or CGS-21680+ZM-241385 were evaluated using one-way ANOVA followed by the Tukey post-hoc test. The percent changes in D2R $K_{\mathrm{i}, \text { High }}, K_{\mathrm{i} \text {, Low }}$ and RH were analyzed with nonparametric Mann-Whitney $U$ test. The $P$ value 0.05 and lower was considered significant.

\section{Results}

\section{Microdialysis}

Basal extracellular DA levels in the rat dorsal striatum of control and cocaine groups were $2.88 \pm 0.19 \mathrm{nM}$ and $3.09 \pm 0.18 \mathrm{nM}$, respectively. As shown in Fig. 1, the subcutaneous injection of cocaine $(1.0 \mathrm{mg} / \mathrm{kg})$ did not significantly affect extracellular DA levels in the rat dorsal striatum.

\section{Biochemical binding}

D2 receptor antagonist $\left[{ }^{3} \mathrm{H}\right]$-raclopride competition assays were performed ex-vivo. The effects of the A2AR agonist CGS-21680 on the affinity values of the D2-like receptor agonist quinpirole were examined in dorsal striatal membranes from in vivo saline (i.e. control vehicle-treated group) and cocaine $(1 \mathrm{mg} / \mathrm{kg})$ injected rats (i.e. acute cocaine group). The proportion of D2Rs in the high-affinity state $(\mathrm{RH}), \mathrm{D} 2 \mathrm{R}$ high affinity $\left(K_{\mathrm{i}, \mathrm{High}}\right)$ and the D2R low affinity $\left(K_{\mathrm{i}, \text { Low }}\right)$ values were determined.

Control vehicle-treated group As seen in Fig. 2a, a small shift to the right in the $\left[{ }^{3} \mathrm{H}\right]$-raclopride competition curves with quinpirole did develop after adding the A2AR agonist CGS-21680 $(100 \mathrm{nM})$ to the striatal membrane preparations. Thus, the D2-like receptor agonist binding to the

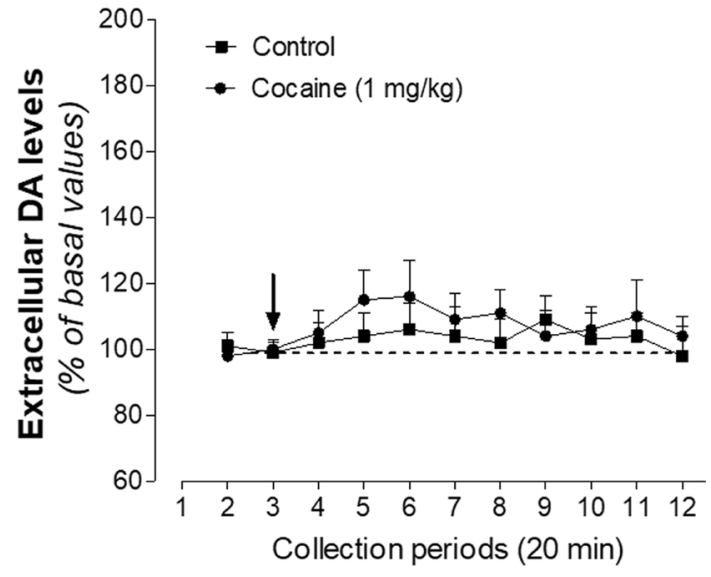

Fig. 1 Effects of cocaine $(1.0 \mathrm{mg} / \mathrm{kg}$; sc) on extracellular dopamine (DA) levels in the rat dorsal striatum. Vehicle treated rats were treated with a subcutaneous saline (i.e. cocaine-vehicle) injection. The arrow indicates cocaine or saline administration. The results are expressed as a percentage of the mean of the three basal values before treatment. Each point represents the means \pm SEM of four animals/group

D2-like receptor high-affinity state was modestly, but significantly, different compared to the control $K_{\mathrm{i} \text {, High }}$ from $34.9 \pm 12.5 \mathrm{nM}$ to $152.6 \pm 27.4 \mathrm{nM}$ in the presence of the A2AR agonist (Fig. 2b). As expected, the A2AR antagonist ZM-241385 $(1 \mu \mathrm{M})$ was able to significantly counteract the increase of the D2R-like $K_{\mathrm{i} \text {, High }}$ values induced by the A2AR agonist leading to values similar to controls (Fig. 2b). Instead, no significant effects were induced by CGS-21680 of the $K_{\mathrm{i} \text {, Low }}$ and RH values (Fig. 2b).

Acute cocaine group In striatal membranes from cocaineinjected rats, the quinpirole binding value to the D2-like receptor high-affinity state $\left(K_{\mathrm{i}, \mathrm{High}}\right.$ value) was $96.2 \pm 52.8 \mathrm{nM}$ and did not significantly differ from that observed in the control vehicle-treated group $(34.9 \pm 12.5 \mathrm{nM}) ; p=0.3017$; $F, \mathrm{DFn}, \mathrm{Dfd}=17.76,3,3)$ by unpaired Student's $t$-test (graph not shown). However, in the presence of the A2AR agonist CGS-21680 (100 nM) a marked right-shift of the $\left[{ }^{3} \mathrm{H}\right]$-raclopride competition binding curve was observed (Fig. 3a). Under these experimental conditions, the D2R $K_{\mathrm{i}, \text { High }}$ value was significantly increased from $96.2 \pm 52.8$ to $1343 \pm 224 \mathrm{nM}$ (Fig. 3b). It demonstrated a strong negative allosteric modulation induced by the A2AR agonist on the quinpirole binding to the D2R high-affinity state. Furthermore, in membranes from cocaine-treated rats also the $K_{\mathrm{i}, \text { Low }}$ value and RH value were markedly and significantly affected by the presence of CGS-21680 (Fig. 3b).

In the cocaine group, the A2AR antagonist ZM-241385 $(1 \mu \mathrm{M})$ was able to significantly counteract the increase of the D2R $K_{\mathrm{i}, \text { High }}, K_{\mathrm{i} \text {, Low }}$ and RH values induced by the A2AR agonist. However, the A2AR antagonist was not 


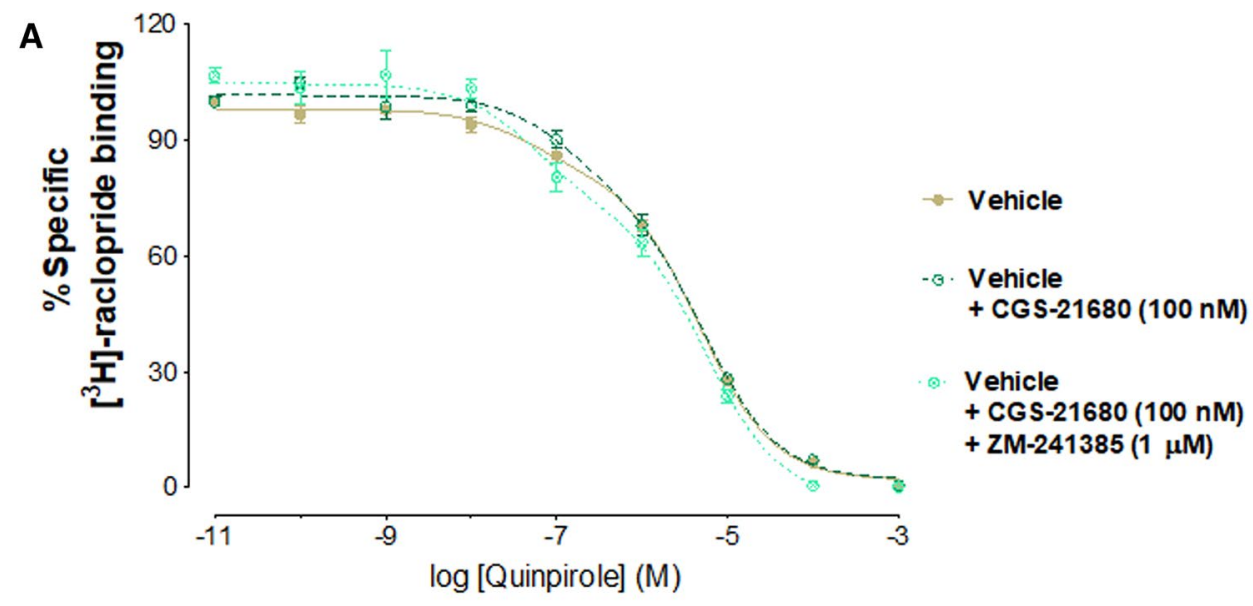

B
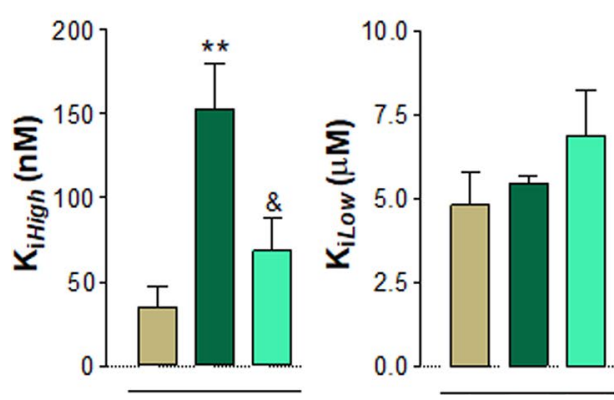

Fig. $2\left[{ }^{3} \mathrm{H}\right]$-raclopride/quinpirole competition binding experiments to determine changes in D2R affinities induced by adenosine A2AR agonist in control (vehicle treated) group. Competition assays were performed in dorsal striatal membrane preparations from the control group with/without the adenosine A2A receptor agonist (CGS-21680) or A2A receptor agonist (CGS-21680) plus antagonist (ZM-241385) as indicated. (+)-Butaclamol $100 \mu \mathrm{M}$ was used to determine the non-specific binding. a The curves based on the values of four rats with each determination performed in duplicates or triplicates are presented in percent of specific binding. The specific binding of the $[3 \mathrm{H}]$-raclopride without quinpirole was defined as one hundred per-

able to fully block the effect of the CGS-21680 (100 nM) on the $K_{\mathrm{i}, \text { Low }}$ and RH values (Fig. $3 \mathrm{~b}$ ).

Control vehicle-treated group vs. acute cocaine group The percent changes induced by the treatment with the CGS$21680(100 \mathrm{nM})$ in $\left[{ }^{3} \mathrm{H}\right]$-raclopride/quinpirole competition conditions on dorsal striatal membranes from control and cocaine groups have been compared. As shown in Fig. 4, CGS-21680 was significantly more effective in lowering the affinity of D2Rs for their agonist in the cocaine group than in the control group. In fact, the CGS-21680 induced percent changes of the measured $K_{\mathrm{i}, \text { High }}, K_{\mathrm{i}, \text { Low }}$ and RH values which were significantly higher in the cocaine group versus the control group $(\stackrel{*}{p}<0.05$; Mann Whitney $U$-test).
Vehicle

$\mathrm{Ki}$, High $=34.9 \pm 12.5 \mathrm{nM}$

$\mathrm{Ki}$, Low $=4.82 \pm 0.96 \mu \mathrm{M}$

$\mathrm{RH}=0.16 \pm 0.02$

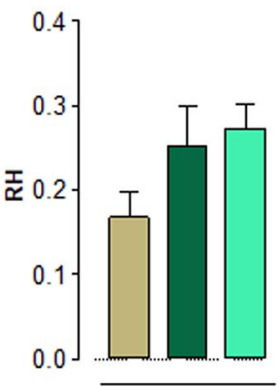

$\square$ Vehicle

+ CGS-21680 (100 nM)

$\mathrm{Ki}$, High $=152.6 \pm 27.4 \mathrm{nM}$

$\mathrm{Ki}$, Low $=5.45 \pm 0.24 \mu \mathrm{M}$

$\mathrm{RH}=0.25 \pm 0.04$

$\square$ Vehicle

+ CGS-21680 (100 nM)

$+\mathrm{ZM}-241385(1 \mu \mathrm{M})$

$\mathrm{Ki}, \mu_{\text {igh }}=68.5 \pm 19.7 \mathrm{nM}$

$\mathrm{Ki}$, Low $=6.87 \pm 1.38 \mu \mathrm{M}$

$\mathrm{RH}=0.27 \pm 0.03$

cent. b The induced changes in the D2R affinities values by A2AR agonist CGS-21680 are presented in absolute values (means \pm SEM; $n=4$, each determination performed in duplicates or triplicates). Statistical analysis was performed by one-way ANOVA followed by the Tukey post-hoc test $(F=8.482)$. $* *(p<0.01)$ : the group of rats treated with CGS-21680 is significantly different compared to the group receiving saline solution (vehicle). ${ }^{\&}(p<0.05)$ : the group of rats treated with CGS-21680+ZM-241385 is significantly different compared to the group receiving CGS-21680 alone. Abbreviations:

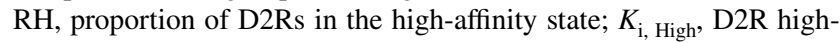
affinity value and $K_{\mathrm{i}, \text { Low }}$, D2R low-affinity value

\section{Discussion}

The major result from the current experiments is the demonstration that acute cocaine in the low dose of $1 \mathrm{mg} / \mathrm{kg}$ which does not increase the dialysate dorsal striatal DA levels, significantly enhances the antagonistic allosteric A2AR-D2R interactions in the rat dorsal striatum. Biochemical binding studies using the D2-like receptor radioligand $\left[{ }^{3} \mathrm{H}\right]$-raclopride in competition with the D2-like receptor agonist quinpirole demonstrated that the percent increases of $K_{\mathrm{i}, \text { High }}$ and $K_{\mathrm{i} \text {, Low }}$ values induced by the A2AR agonist CGS-21680 were significantly more marked in membrane preparations from cocaine-injected rats. 

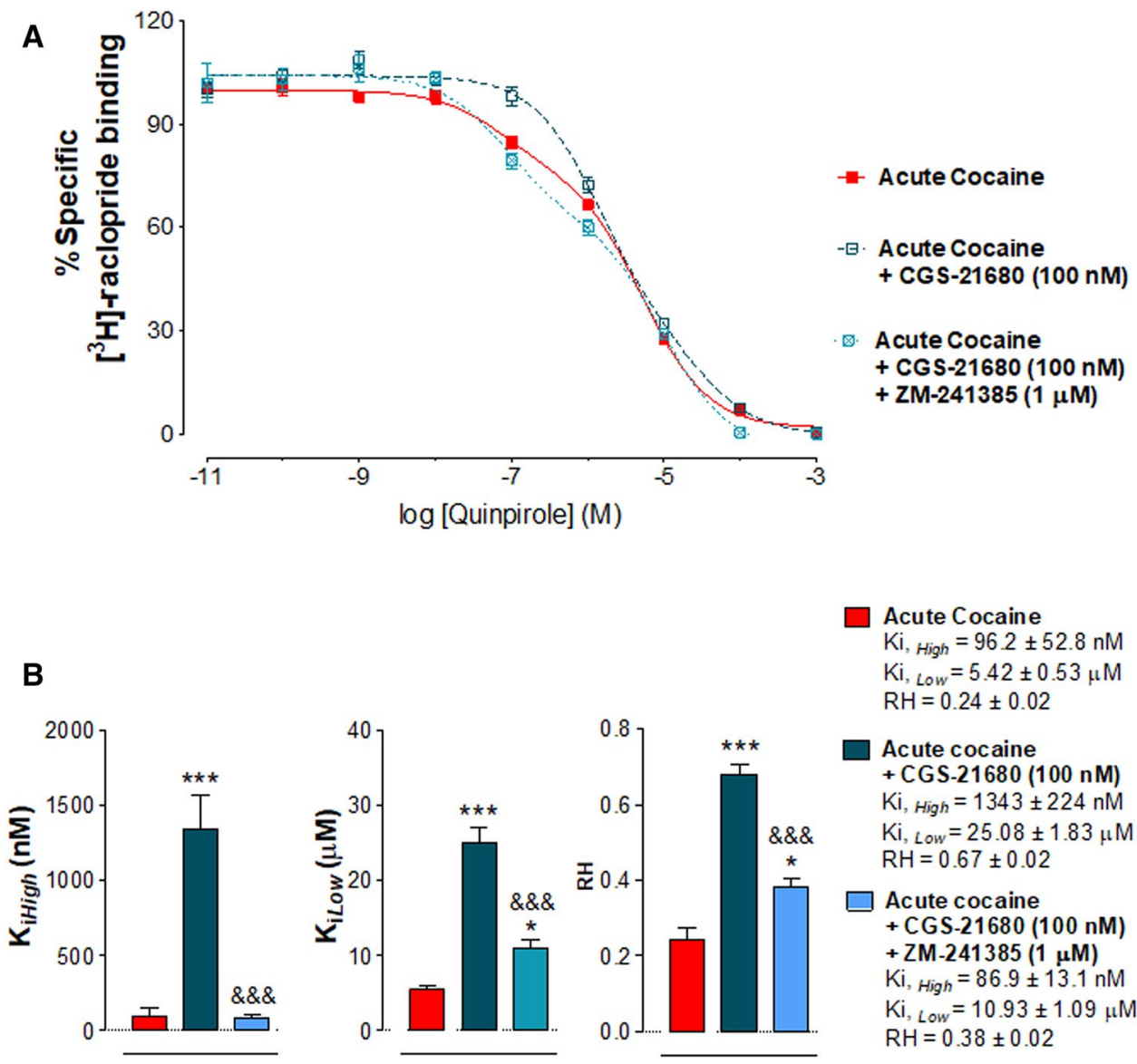

Acute Cocaine

$\mathrm{Ki}, \mu_{\text {igh }}=96.2 \pm 52.8 \mathrm{nM}$

$\mathrm{Ki}_{\text {Low }}=5.42 \pm 0.53 \mu \mathrm{M}$

$\mathrm{RH}=0.24 \pm 0.02$

Acute cocaine

+ CGS-21680 (100 nM)

$\mathrm{Ki}, \mathrm{High}=1343 \pm 224 \mathrm{nM}$

$\mathrm{Ki}$, Low $=25.08 \pm 1.83 \mu \mathrm{M}$

$\mathrm{RH}=0.67 \pm 0.02$

$\square$ Acute cocaine

+ CGS-21680 (100 nM)

$+\mathrm{ZM}-241385$ (1 $\mu \mathrm{M})$

$\mathrm{Ki}$, High $=86.9 \pm 13.1 \mathrm{nM}$

$\mathrm{Ki}_{\text {, Low }}=10.93 \pm 1.09 \mu \mathrm{M}$

$\mathrm{RH}=0.38 \pm 0.02$

Fig. $3\left[{ }^{3} \mathrm{H}\right]$-raclopride/quinpirole competition binding experiments to evaluate the allosteric modulation produced by adenosine A2A agonist on the D2R binding in the acute cocaine group. Competition assays were performed in dorsal striatal membrane preparations from the acute cocaine group with/without the adenosine A2A receptor agonist (CGS-21680) or A2A receptor agonist (CGS-21680) plus antagonist (ZM-241385) as indicated. (+)-Butaclamol $100 \mu \mathrm{M}$ was used to determine the non-specific binding. a The curves based on the values of four rats with each determination performed in duplicates or triplicates are presented in percent of specific binding. The specific binding of the $[3 \mathrm{H}]$-raclopride without quinpirole was defined

Looking into more details of the observed antagonistic A2AR-D2R interactions, it is also clear that in agreement with previous work $[2,4,7]$ the A2AR agonist in control rats only produced a significant increase in the $K_{\mathrm{i} \text {, High }}$ values with no effects on the $K_{\mathrm{i} \text {, Low }}$ values and on the proportion of D2R in the high-affinity state (RH). However, in the acute cocaine group, the A2AR agonist produced a significant enhancement of the $K_{\mathrm{i} \text {, Low }}$ and RH values. This is of interest since these actions did not develop in the vehicle-injected group. When comparing the percent changes induced by the A2AR agonist on $K_{\mathrm{i}, \mathrm{High}}, K_{\mathrm{i} \text {, Low }}$ and $\mathrm{RH}$ values in controls and acutely treated cocaine rats, we found that these three parameters were all significantly enhanced in the cocaine group vs. the control group. as one hundred percent. $\mathbf{b}$ The induced changes in the D2R affinities values by A2AR agonist CGS-21680 are presented in absolute values (means \pm SEM; $n=4$, each determination performed in duplicates or triplicates). Statistical analysis was performed by one-way ANOVA followed by the Tukey post-hoc test $(F=29.47)$. *** $(p<0.001)$ and $*(p<0.05)$ : significant differences compared to the group receiving only acute cocaine. ${ }^{\& \& \&}(p<0.001)$ : the group of rats treated with CGS-21680+ZM-241385 is significantly different compared to the group receiving CGS-21680 alone. Abbreviations: RH, proportion of D2Rs in the high-affinity state; $K_{\mathrm{i}, \text { High }}$, D2R high-affinity value and $K_{\mathrm{i}, \text { Low }}$, D2R low-affinity value

Thus, the enhanced A2AR-mediated allosteric inhibition involves both the high and low-affinity D2R agonist binding sites in the cocaine treated group. There is an increase in the proportion of $\mathrm{D} 2 \mathrm{R}$ receptors in the high-affinity state after sc cocaine $1 \mathrm{mg} / \mathrm{kg}$ injection, but the D2R in the high-affinity state shows a significantly reduced affinity for quinpirole under these experimental conditions as seen from the $K_{\mathrm{i}, \mathrm{High}}$ values.

The present findings are in sharp contrast to the results obtained in the experiments on cocaine self-administration in which the antagonistic A2AR-D2R interactions induced by CGS-21680 in yoked saline rats were not present in dorsal striatum of cocaine-exposed rats. This discrepancy can be the results of the different experimental conditions (i.e. acute vs. chronic treatment involving in addition also drug-seeking 


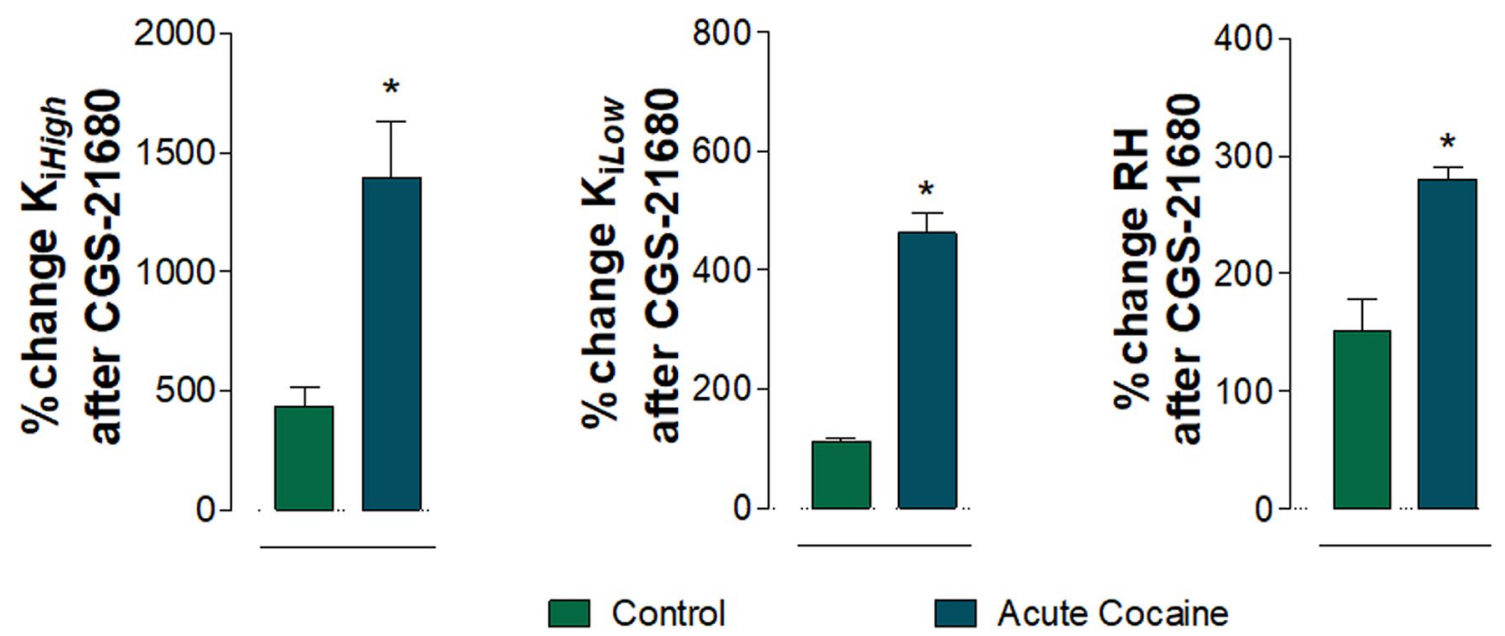

Fig. 4 A2A agonist CGS-21680 (100 nM) induced changes in D2R binding, comparing the cocaine group and the control (vehicle treated) group given in percent of values in the absence of CGS21680 with regard to the RH, $K_{\mathrm{i}, \text { High }}$ and $K_{\mathrm{i}, \text { Low }}$ values. Means \pm SEM are given for four independent experiments performed in tripli-

aspects) as well as to the different doses of cocaine administered in the present and in the cocaine self-administration studies. As demonstrated and in line with previous studies [30], cocaine in the dose used in the present experiments $(1 \mathrm{mg} / \mathrm{kg}, \mathrm{sc})$, did not significantly increase dialysate dorsal striatal DA levels. Therefore, it seems unlikely that the enhancement of the antagonistic allosteric receptor-receptor within A2AR-D2R interactions observed in the cocaine group in the rat dorsal striatum is mediated by the binding of the drug to the DAT. Thus, this DAT-independent action of cocaine at the low dose may instead involve another target for the drug, namely the sigma1R [21].

Previous in vitro studies demonstrated that cocaine in nanomolar concentrations appear to alter the allosteric sigma1-D2 receptor-receptor interactions in the cellular model and in the striatal sigma1-D2R heterocomplexes causing an increase of Gi/o mediated D2R signaling [38, 39]. The sigma1R is recruited to the plasma membrane by cocaine where it inter alia interacts with D1R and D2R [21, 26, 27]. The mechanism may, therefore, be an increased and rapid formation of A2AR-D2R-sigma1R heteroreceptor complexes [8] due to an increased recruitment of sigma1Rs to the plasma membrane induced by cocaine at low concentrations/doses. The increase in sigma1R bound to D2R in the plasma membrane may, in turn, increase the affinity of A2AR to bind to the D2R. Increased formation of A2AR-D2R-sigma1R heterocomplexes can, therefore, take place after acute cocaine injection, not increasing extracellular DA levels.

Furthermore, cocaine by binding to sigma1Rs may enhance the allosteric inhibition exerted by the A2AR agonist on D2R recognition site as observed in the current experiments through the enhanced inhibitory A2AR-D2R interactions in putative cate. Statistical analysis was performed by Mann-Whitney $U$ test. $*(p<0.05)$ : the group of acute cocaine is significantly different compared to the control group with regard to $K_{\mathrm{i}, \text { High }}, K_{\mathrm{i} \text {, Low }}$, and RH values. Abbreviations: $\mathrm{RH}$, proportion of D2Rs in the high-affinity state; $K_{\mathrm{i}, \text { High }}$, D2R high-affinity value and $K_{\mathrm{i}, \text { Low }}, \mathrm{D} 2 \mathrm{R}$ low-affinity value

A2AR-D2R-Sigma1R complexes. The A2AR-D2R-sigma1R heterocomplexes are mainly located in the dorsal striato-pallidal GABA pathway mediating motor inhibition [40]. Thus, the enhancement of the antagonistic allosteric A2AR-D2R interactions in the rat dorsal striatum, and the consequent reduction of the inhibitory actions of the D2R protomer in this state, should lead to enhancement of motor inhibition with low concentrations of cocaine lacking effects on the DAT and targeting the sigma1R. Further studies are necessary to establish this intriguing hypothesis.

Taken together, the current results indicate that a low acute dose of cocaine, not associated with an increase in dorsal striatal extracellular DA levels, enhances the allosteric inhibitory A2AR-D2R receptor-receptor interactions in the rat dorsal striatum. The enhancement of A2AR-induced inhibition on D2R protomer recognition is marked both for the $K_{\mathrm{i}, \text { High }}$ and $K_{\mathrm{i} \text {, Low }}$ which becomes strongly increased in the cocaine group. In such a state, increased motor inhibition may develop since enhanced A2AR-induced inhibition of $\mathrm{D} 2 \mathrm{R}$ protomer recognition develops in a putative A2AR-D2R-sigma1R complex in which cocaine likely binds to the sigma1R. This heteroreceptor complex is located in the dorsal striato-pallidal GABA neurons that mediates motor inhibition and increases its activity due to reduced inhibitory D2R function involving reduced $D 2 R$ protomer recognition. This finding is of substantial interest since in maintenance of rodent cocaine self-administration the antagonistic A2A-D2 receptor-receptor interactions in dorsal striatum are blocked [7]. This suggests that differential changes develop in the antagonistic allosteric A2A-D2 receptor-receptor interactions in the dorsal striatum after acute cocaine treatment in low doses versus cocaine self-administration. 
Acknowledgements Open access funding provided by Karolinska Institute. The work was supported by Vetenskapsrådet (62X-0071550-3), ParkinsonFonden (2017) to KF, by China Scholarship Council to ZZL and by KI Forskningsstiftelser (2016-2017) and Hjärnfonden (FO2018-0286, FO2019-0296) to D.O.B-E. D.O.B-E belongs to the "Academia de Biólogos Cubanos" group.

Author contributions We declare that all authors meet the criteria for authorship according to the ICMJE. KF, LF, DOBE, ST, MF, KW, SB, ZZL and WR-F designed methods for the experiments, analyzed and interpreted the results. SB, ST, LF and KF co-designed and worked together on the microdialysis experiments. WR-F, ZZL, KW, MF, DOBE and KF co-designed and worked together on the radioligand binding.

\section{Compliance with ethical standards}

Conflict of interest The authors declare no conflict of interest.

Open Access This article is licensed under a Creative Commons Attribution 4.0 International License, which permits use, sharing, adaptation, distribution and reproduction in any medium or format, as long as you give appropriate credit to the original author(s) and the source, provide a link to the Creative Commons licence, and indicate if changes were made. The images or other third party material in this article are included in the article's Creative Commons licence, unless indicated otherwise in a credit line to the material. If material is not included in the article's Creative Commons licence and your intended use is not permitted by statutory regulation or exceeds the permitted use, you will need to obtain permission directly from the copyright holder. To view a copy of this licence, visit http://creativecommons.org/licenses/by/4.0/.

\section{References}

1. Ferre S, von Euler G, Johansson B, Fredholm BB, Fuxe K. Stimulation of high-affinity adenosine $\mathrm{A} 2$ receptors decreases the affinity of dopamine D2 receptors in rat striatal membranes. Proc Natl Acad Sci USA. 1991;88(16):7238-41.

2. Fuxe K, Ferre S, Zoli M, Agnati LF. Integrated events in central dopamine transmission as analyzed at multiple levels. Evidence for intramembrane adenosine A2A/dopamine D2 and adenosine A1/dopamine D1 receptor interactions in the basal ganglia. Brain Res Brain Res Rev. 1998;26(2-3):258-73.

3. Fuxe K, Ferre S, Genedani S, Franco R, Agnati LF. Adenosine receptor-dopamine receptor interactions in the basal ganglia and their relevance for brain function. Physiol Behav. 2007;92(1-2):210-7.

4. Fuxe K, Marcellino D, Borroto-Escuela DO, Guescini M, Fernandez-Duenas V, Tanganelli S, et al. Adenosine-dopamine interactions in the pathophysiology and treatment of CNS disorders. CNS Neurosci Ther. 2010;16(3):e18-42.

5. Borroto-Escuela DO, Romero-Fernandez W, Tarakanov AO, Gomez-Soler M, Corrales F, Marcellino D, et al. Characterization of the A2AR-D2R interface: focus on the role of the C-terminal tail and the transmembrane helices. Biochem Biophys Res Commun. 2010;402(4):801-7.

6. Beggiato S, Antonelli T, Tomasini MC, Borelli AC, Agnati LF, Tanganelli S, et al. Adenosine A2A-D2 receptor-receptor interactions in putative heteromers in the regulation of the striato-pallidal gaba pathway: possible relevance for parkinson's disease and its treatment. Curr Protein Pept Sci. 2014;15(7):673-80.
7. Pintsuk J, Borroto-Escuela DO, Pomierny B, Wydra K, Zaniewska M, Filip M, et al. Cocaine self-administration differentially affects allosteric A2A-D2 receptor-receptor interactions in the striatum. Relevance for cocaine use disorder. Pharmacol Biochem Behav. 2016;144:85-91.

8. Borroto-Escuela DO, Wydra K, Filip M, Fuxe K. A2AR-D2R heteroreceptor complexes in cocaine reward and addiction. Trends Pharmacol Sci. 2018;39(12):1008-200.

9. Borroto-Escuela DO, Rodriguez D, Romero-Fernandez W, Kapla J, Jaiteh M, Ranganathan A, et al. Mapping the interface of a GPCR dimer: a structural model of the A2A adenosine and D2 dopamine receptor heteromer. Front Pharmacol. 2018;9:829.

10. Trifilieff P, Rives ML, Urizar E, Piskorowski RA, Vishwasrao $\mathrm{HD}$, Castrillon J, et al. Detection of antigen interactions ex vivo by proximity ligation assay: endogenous dopamine D2-adenosine $\mathrm{A} 2 \mathrm{~A}$ receptor complexes in the striatum. Biotechniques. 2011;51(2):111-8.

11. Filip M, Zaniewska M, Frankowska M, Wydra K, Fuxe K. The importance of the adenosine $\mathrm{A}(2 \mathrm{~A})$ receptor-dopamine $\mathrm{D}(2)$ receptor interaction in drug addiction. Curr Med Chem. 2012;19(3):317-55.

12. Fuxe K, Agnati LF, Jacobsen K, Hillion J, Canals M, Torvinen $\mathrm{M}$, et al. Receptor heteromerization in adenosine A2A receptor signaling: relevance for striatal function and Parkinson's disease. Neurology. 2003;61(11 Suppl 6):S19-23.

13. Borroto-Escuela DO, Narvaez M, Wydra K, Pintsuk J, Pinton L, Jimenez-Beristain A, et al. Cocaine self-administration specifically increases A2AR-D2R and D2R-sigma1R heteroreceptor complexes in the rat nucleus accumbens shell. Relevance for cocaine use disorder. Pharmacol Biochem Behav. 2017;155:24-31.

14. Canals M, Marcellino D, Fanelli F, Ciruela F, de Benedetti P, Goldberg SR, et al. Adenosine A2A-dopamine D2 receptorreceptor heteromerization: qualitative and quantitative assessment by fluorescence and bioluminescence energy transfer. J Biol Chem. 2003;278(47):46741-9.

15. Fink JS, Weaver DR, Rivkees SA, Peterfreund RA, Pollack AE, Adler EM, et al. Molecular cloning of the rat A2 adenosine receptor: selective co-expression with D2 dopamine receptors in rat striatum. Brain Res Mol Brain Res. 1992;14(3):186-95.

16. Fuxe K, Ferre S, Canals M, Torvinen M, Terasmaa A, Marcellino D, et al. Adenosine A2A and dopamine D2 heteromeric receptor complexes and their function. J Mol Neurosci. 2005;26(2-3):209-20.

17. Fuxe K, Ungerstedt U. Action of caffeine and theophyllamine on supersensitive dopamine receptors: considerable enhancement of receptor response to treatment with DOPA and dopamine receptor agonists. Med Biol. 1974;52(1):48-544.

18. Mandt BH, Copenhagen LI, Zahniser NR, Allen RM. Escalation of cocaine consumption in short and long access self-administration procedures. Drug Alcohol Depend. 2015;149:166-72.

19. Borroto-Escuela DO, Wydra K, Pintsuk J, Narvaez M, Corrales F, Zaniewska M, et al. Understanding the functional plasticity in neural networks of the Basal Ganglia in cocaine use disorder: a role for allosteric receptor-receptor interactions in A2A-D2 heteroreceptor complexes. Neural Plast. 2016;2016:4827268.

20. Mavlyutov TA, Duellman T, Kim HT, Epstein ML, Leese C, Davletov BA, et al. Sigma-1 receptor expression in the dorsal root ganglion: Reexamination using a highly specific antibody. Neuroscience. 2016;331:148-57.

21. Kourrich S, Su TP, Fujimoto M, Bonci A. The sigma-1 receptor: roles in neuronal plasticity and disease. Trends Neurosci. 2012;35(12):762-71.

22. Mavlyutov TA, Epstein M, Guo LW. Subcellular localization of the sigma- 1 receptor in retinal neurons-an electron microscopy study. Sci Rep. 2015;5:10689. 
23. Su TP. Non-canonical targets mediating the action of drugs of abuse: cocaine at the sigma-1 receptor as an example. Front Neurosci. 2019;13:761.

24. Fontanilla D, Johannessen M, Hajipour AR, Cozzi NV, Jackson $\mathrm{MB}$, Ruoho AE. The hallucinogen $N, N$-dimethyltryptamine (DMT) is an endogenous sigma-1 receptor regulator. Science. 2009;323(5916):934-7.

25. Sharkey J, Glen KA, Wolfe S, Kuhar MJ. Cocaine binding at sigma receptors. Eur J Pharmacol. 1988;149(1-2):171-4.

26. Navarro G, Moreno E, Bonaventura J, Brugarolas M, Farre $\mathrm{D}$, Aguinaga D, et al. Cocaine inhibits dopamine D2 receptor signaling via sigma-1-D2 receptor heteromers. PLoS One. 2013;8(4):e61245.

27. Navarro G, Moreno E, Aymerich M, Marcellino D, McCormick PJ, Mallol J, et al. Direct involvement of sigma-1 receptors in the dopamine D1 receptor-mediated effects of cocaine. Proc Natl Acad Sci USA. 2010;107(43):18676-81.

28. Borroto-Escuela DO, Narvaez M, Romero-Fernandez W, Pinton L, Wydra K, Filip M, et al. Acute cocaine enhances dopamine $\mathrm{D} 2 \mathrm{R}$ recognition and signaling and counteracts D2R internalization in Sigma1R-D2R heteroreceptor complexes. Mol Neurobiol. 2019;56(10):7045-55. https://doi.org/10.1007/s1203 5-019-1580-8.

29. Matsumoto RR, Liu Y, Lerner M, Howard EW, Brackett DJ. Sigma receptors: potential medications development target for anti-cocaine agents. Eur J Pharmacol. 2003;469(1-3):1-12.

30. Carboni E, Imperato A, Perezzani L, Di Chiara G. Amphetamine, cocaine, phencyclidine and nomifensine increase extracellular dopamine concentrations preferentially in the nucleus accumbens of freely moving rats. Neuroscience. 1989;28(3):653-61.

31. Martin-Fardon R, Arnaud M, Rousseau E, Kamenka JM, Privat A, Vignon J. $N$-[1-(2-Benzo(b)thiophenyl)cyclohexyl]piperidine (BTCP) and cocaine induce similar effects on striatal dopamine: a microdialysis study in freely moving rats. Neurosci Lett. 1996;211(3):179-82.
32. Gonder JC, Laber K. A renewed look at laboratory rodent housing and management. ILAR J. 2007;48(1):29-36.

33. Romero-Fernandez W, Batista-Castro Z, De Lucca M, Ruano A, Garcia-Barcelo M, Rivera-Cervantes M, et al. The 1, 2, 3 of laboratory animal experimentation. Rev Peru Med Exp Salud Publica. 2016;33(2):288-99.

34. Hartung T. Comparative analysis of the revised directive 2010/63/ EU for the protection of laboratory animals with its predecessor 86/609/EEC—a t4 report. ALTEX. 2010;27(4):285-303.

35. Wydra K, Golembiowska K, Zaniewska M, Kaminska K, Ferraro L, Fuxe K, et al. Accumbal and pallidal dopamine, glutamate and GABA overflow during cocaine self-administration and its extinction in rats. Addict Biol. 2013;18(2):307-24.

36. Ferraro L, O'Connor WT, Beggiato S, Tomasini MC, Fuxe K, Tanganelli S, et al. Striatal NTS1, dopamine D2 and NMDA receptor regulation of pallidal GABA and glutamate release-a dual-probe microdialysis study in the intranigral 6-hydroxydopamine unilaterally lesioned rat. Eur J Neurosci. 2012;35(2):207-20.

37. Paxinos $\mathrm{G}$, Watson $\mathrm{C}$, editors. The rat brain in stereotaxic coordinates: Sydney. Orlando: Academic Press; 1986.

38. Beggiato S, Borelli AC, Borroto-Escuela D, Corbucci I, Tomasini MC, Marti M, et al. Cocaine modulates allosteric D2-sigma1 receptor-receptor interactions on dopamine and glutamate nerve terminals from rat striatum. Cell Signal. 2017;40:116-24.

39. Church WH, Justice JB Jr, Byrd LD. Extracellular dopamine in rat striatum following uptake inhibition by cocaine, nomifensine and benztropine. Eur J Pharmacol. 1987;139(3):345-8.

40. Surmeier DJ, Graves SM, Shen W. Dopaminergic modulation of striatal networks in health and Parkinson's disease. Curr Opin Neurobiol. 2014;29:109-17.

Publisher's Note Springer Nature remains neutral with regard to jurisdictional claims in published maps and institutional affiliations.

\section{Affiliations}

\section{Wilber Romero-Fernandez ${ }^{1,2} \cdot$ Zilong Zhou $^{2,3} \cdot$ Sarah Beggiato $^{4} \cdot$ Karolina Wydra $^{5} \cdot$ Malgorzata Filip $^{5}$. Sergio Tanganelli ${ }^{6}$. Dasiel O. Borroto-Escuela ${ }^{2,7,8} \cdot$ Luca Ferraro $^{4} \cdot$ Kjell Fuxe $^{2}$}

Wilber Romero-Fernandez

wromfdez@gmail.com

Zilong Zhou

zilongzhou@outlook.com

Sarah Beggiato

bggsrh@unife.it

Karolina Wydra

wydra@if-pan.krakow.pl

Malgorzata Filip

mal.fil@if-pan.krakow.pl

Sergio Tanganelli

tgs@unife.it

Dasiel O. Borroto-Escuela

Dasiel.Borroto.Escuela@ki.se

Luca Ferraro

frl@unife.it

1 Science for Life Laboratory, Department of Cell and Molecular Biology, Uppsala, Sweden
2 Department of Neuroscience, Karolinska Institutet, Biomedicum 8B Solnavägen 9, 17165 Solna, Sweden

3 National Engineering Laboratory for Druggable Gene and Protein Screening, Northeast Normal University, Changchun, China

4 Department of Life Sciences and Biotechnology (SVEB), and LTTA Center, University of Ferrara, Ferrara, Italy

5 Maj Institute of Pharmacology, Department of Drug Addiction Pharmacology, Polish Academy of Sciences, Kraków, Poland

6 Department of Medical Sciences, University of Ferrara, Ferrara, Italy

7 Department of Biomolecular Science, Section of Physiology, University of Urbino, Campus Scientifico Enrico Mattei, Urbino, Italy

8 Observatorio Cubano de Neurociencias, Grupo Bohío-Estudio, Yaguajay, Cuba 